\title{
O USO DO JOGO TANGRAM COMO MATERIAL PEDAGÓGICO MATEMÁTICO PARA ALUNOS COM SURDEZ
}

\author{
THE USE OF THE TANGRAM GAME AS A MATHEMATICAL PEDAGOGICAL \\ MATERIAL FOR A DEAF STUDENTS
}

\author{
Francisca Aglaiza Romão Sedrim Gonçalves ${ }^{1}$
}

\begin{abstract}
RESUMO
Este é um relato de experiência realizada em 2019 com uma aluna surda que mesmo frequentando o primeiro ano do Ensino Médio, apresentava dificuldades de compreender o conceito e aplicabilidade de área de figuras planas elementares, por exemplo do quadrado. Diante da dificuldade apresentada pela discente em compreender para quê e como calcular a área de figuras geométricas planas, optou-se pelo uso do material didático auxiliar (quebra cabeças de origem chinesa chamado Tangram) aliado a uma metodologia lúdica fundamentada em Pimentel (2014, p. 5) e Lorenzato (2008, p. 20-21) como estratégia didática a fim de promover a compreensão e o envolvimento da aluna com o componente curricular, buscando inicialmente atrair a educanda para o quebra-cabeças e posteriormente para o saber em pauta (área de figuras planas). A abordagem se deu a priori por meio da manipulação das peças, construção de um novo jogo igual e comparações entre os mesmos. Durante a manuseio, além do objetivo principal (construir o conceito de área e aplica-lo), foi possível compreender, construir e aplicar outros conhecimentos envolvendo Geometria como congruência, paralelismo e perpendicularismo, por exemplo. $\mathrm{O}$ manuseio favoreceu o entendimento do assunto que a aluna apresentava dificuldade e abriu possibilidades para além da manipulação de fórmulas: a compreensão e aplicabilidade do que se estava sendo construído. Portanto, o texto busca ressaltar a importância do lúdico em situações didáticas na diversidade. A confiança que a discente demonstrou ao afirmar as últimas conclusões baseada nos últimos resultados que obteve foram importantes não somente para os resultados de área, mas também de percepção de espaço, de outros elementos básicos da Geometria e de sua familiaridade com a Matemática.
\end{abstract}

Palavras-chave: Tangram; Matemática; Área de figuras planas; Surdez.

\begin{abstract}
This is an experience report conducted in 2019 with a deaf student that even attending the first year of high school, had difficulty understanding the concept and applicability area of simple plane figures, for example square. Given the difficulty presented by the student to understand for what and how to calculate the area of plane geometric figures, we opted for the use of didactic material aid (puzzle of Chinese origin called Tangram) combined with a playful methodology based on Pimentel (2014, p 5) and Lorenzato (2008, p. 20-21) as a didactic strategy in order to promote the student's understanding and involvement with the curricular component, initially trying to attract the student to the puzzle and later to the knowledge on the agenda (area of flat figures). The approach took place initially through the manipulation of the pieces, construction of

\footnotetext{
${ }^{1}$ Mestra em Matemática (UFCA). Professora de Matemática da Educação Básica (SEDUC), Jardim, Ceará, Brasil e Cedro, Pernambuco, Brasil. Endereço para correspondência: Rua Fco Filgueira Sampaio, 65, Centro, Cedro, Pernambuco, Brasil, CEP: 56130-000. E-mail: aglaizaromao@gmail.com.
}

ORCID iD: https://orcid.org/0000-0002-4999-9906. 
a new equal game and comparisons between them. During the move, in addition to the main objective (building the concept of area and applying it), it was possible to understand, build and apply other knowledge involving Geometry such as congruence, parallelism and perpendicularism, for example. The contact with the game favored the understanding of the subject that the student had difficulty and enabled more than the application of formulas: the understanding and applicability of what was being built. Therefore, the text emphasizes the importance of playfulness in didactic situations in diversity. The confidence that the student showed when affirming the latest conclusions based on the last results obtained was important not only for the area results, but also for the perception of space, other basic elements of Geometry and their familiarity with Mathematics.

Keywords: Tangram; Mathematics; Flat figures area; Deafness. 


\section{Introdução}

Trabalhar matemática utilizando recursos lúdicos é um meio bem viável para alcançar bons resultados. Há uma vasta produção afirmando que quando o aluno apalpa materiais ou visualiza movimentos, por exemplo, ele tira conclusões mais precisas, entende melhor, constrói efetivamente seu conhecimento e ganha maturidade para lidar com problemas posteriores de natureza semelhante.

Por meio dos jogos as crianças não apenas vivenciam situações que se repetem, mas aprendem a lidar com símbolos e a pensar por analogia (jogos simbólicos): os significados das coisas passam a ser imaginados por elas. Ao criarem essas analogias, tornam-se produtoras de linguagens, criadoras de convenções, capacitando-se para se submeterem a regras e dar explicações . (PCN, p. 36)

O lúdico influencia positivamente no desenvolvimento do aluno, seja ele ouvinte ou surdo. No caso do educando com surdez, trabalhar o lúdico valorizando especialmente o visual é uma estratégia extremamente positiva, pois a visão é um canal de forte comunicação do aluno surdo, logo quanto mais visuais forem as aulas e as explicações, mais acessibilidade ao surdo está sendo oferecida.

No caso da Matemática, aulas bastante expositivas, sem muita possibilidade de interação e manipulação dá ao aluno a ideia de que a matemática é rígida e está sempre impondo, como descreve D’Ambrósio:

Os professores em geral mostram a matemática como um corpo de conhecimentos acabado e polido. Ao aluno não é dado em nenhum momento a oportunidade ou gerada a necessidade de criar nada, nem mesmo uma solução mais interessante. $\mathrm{O}$ aluno assim, passa a acreditar que na aula de matemática o seu papel é passivo e desinteressante. (D’AMBRÓSIO, 1989, p. 2)

Este trabalho é um relato de experiência que objetiva mostrar quão eficaz pode ser o uso do Tangram no ensino de matemática para uma aluna surda, possibilitando a criação e a investigação por meio do jogo.

O Tangram é um jogo que trabalha a concentração e a ludicidade do aluno e por possuir peças de tamanhos e formatos diferentes pode ser um bom aliado nas abordagens que envolvem Geometria Plana, além de tratar-se de um jogo simples, de baixo custo, que pode ser confeccionado junto com o educando.

$\mathrm{O}$ uso de materiais concretos e manipuláveis fomentam o desenvolvimento matemático. "O jogo e a brincadeira permitem ao aluno criar, imaginar, fazer de conta, 
funciona como laboratório de aprendizagem, permitem ao aluno experimentar, medir, utilizar, equivocar-se e fundamentalmente aprender" (VYGOTSKY e LEONTIEV, 1998, p. 23).

Só ao manipular as peças do jogo, o aluno depara-se com figuras geométricas elementares que lhe permitem verificar simetrias, semelhanças, realizar rotações, translações, entre outras comparações/manipulações. "Ao visualizar objetos geométricos, o indivíduo passa a ter controle sobre o conjunto das operações mentais básicas exigidas no trato da geometria". (KALEFF, 2003, p. 16).

Com base nas referências já citadas, o jogo Tangram foi usado como recurso pedagógico no Atendimento Educacional Especializado - AEE para o ensino de área de figuras planas, de forma individual, com uma aluna surda regularmente matriculada no $1^{\circ}$ Ensino Médio de uma escola da rede pública estadual que relatou ter dificuldade no assunto durante todo o Ensino Fundamental. O AEE da aluna ocorre na Sala de Recursos Multifuncional - SRM da escola mesma escola. Cabe aqui esta observação quanto a localização da sala porque os alunos de AEE, por terem duas matrículas, podem ser matriculados no ensino regular em uma escola e usufruir do atendimento educacional especializado em outra.

\section{O tangram}

O jogo que protagoniza este relato é um quebra-cabeças geométrico com origem chinesa praticado há muitos séculos no Oriente. Existem algumas lendas e mitos que configuram sua origem, uma delas é que um monge chinês descuidadamente deixou cair uma porcelana quadrada, a mesma quebrou-se em sete pedaços e o mesmo conseguiu, a partir da porcelana fragmentada construir várias figuras distintas. Por causa desta versão, o jogo é conhecido com a "tábua das sete sabedorias" ou "tábua das sete sutilezas" (SILVA, 2007, p.4).

A regra geral do jogo é que ao montar as figuras, todas as peças sejam utilizadas. Em contexto escolar há uma "licença pedagógica" para o manuseio da forma que melhor atenda os objetivos da tarefa, podendo o professor junto com o aluno criar novas regras quando acharem pertinente. A figura a seguir (Figura 1), apresenta o quadrado composto pelas sete peças que compõem o quebra-cabeças. 
Figura 1 - Tangram

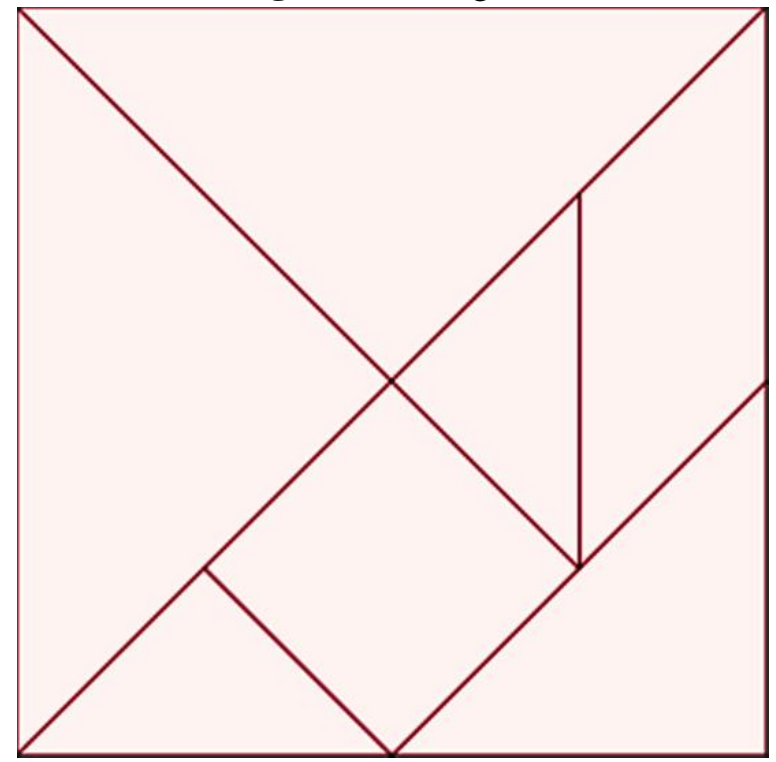

Fonte: Elaborada pela autora (2021)

Conforme a Figura 1, jogo é composto por sete peças das quais dois triângulos maiores são congruentes e ocupam $50 \%$ da área total do quadrado e a outra metade do quadrado é composta por três triângulos, sendo dois pequenos congruentes e um médio, e, dois paralelogramos, sendo um deles quadrado.

De origem menos antiga que o Tangram tradicional, o da figura 1 (Figura 1), existem outros quebra-cabeças com objetivos semelhantes (manipular suas peças dando origem a novas figuras) com formatos diferentes: retângulo, coração, oval e circular, porém não ganharão destaque neste texto por não terem feito parte da experiência relatada.

\section{Detalhamento da situação: problema versus solução}

O Atendimento Educacional Escpecializado - AEE, é um atendimento realizado no contra turno do ensino regular que busca identificar quais são as barreiras na escola comum que impedem ou dificultam o desenvolvimento dos alunos com algum tipo de deficiência e/ou dificuldades de aprendizagem, regulamentado pela Lei de Diretrizes e Bases da Educação Nacional - LDBN, Lei No 9394/1996 e normatizado pelo decreto $\mathrm{N}^{\circ}$ $7.611 / 2011$.

No caso do aluno com surdez, por sua língua natural ser a língua de sinais, ou seja, sua Primeira Língua - L1 ser a Libras, o AEE é principalmente destinado para o ensino 
da Segunda Língua - L2, o Português na modalidade escrita, numa perspectiva bilíngue, respeitando a cultura e o direito de ser surdo e alfabetizando o indivíduo na língua oficial do país. O ensino da língua portuguesa como L2 não fecha espaço para outras aprendizagens que estão também atreladas ao Português e ao ensino regular, pelo contrário, os professores do AEE e da sala de aula regular mantém contato, trocam vivências e acompanham juntos a evolução do educando no tocante às competências e habilidades em todas as áreas do conhecimento, buscando valorizar suas potencialidades e sanar suas dificuldades. Assim, o atendimento preza pela garantia do desenvolvimento integral do indivíduo.

Conforme o Manual de Orientação do Programa de Implantação de Salas de Recursos Multifuncionais do Ministério da Educação, o atendimento é realizado de forma individual ou em pequenos grupos, de acordo com as necessidades educacionais específicas. Na situação a ser descrita, a escola campo deste relato tinha apenas duas matrículas de discentes com surdez e seus atendimentos ocorriam da seguinte forma: um em dupla e um individual.

O objetivo do atendimento em dupla era para que os alunos interagissem entre si, houvesse uma troca, mantivessem a língua de sinais viva e fomentassem sua própria cultura, pois " é importante que o surdo se mantenha integrado em sua comunidade, se relacione com seus pares" (DIZEU; CAPORALI, 2005, p. 593). No momento individual buscava atender melhor as particularidades de cada aluno conforme suas idades/séries. No caso da educanda que protagoniza este relato, o que será descrito a seguir faz parte de atendimentos individuais.

No ano de 2019, uma discente surda, que será chamada neste texto de Sandra, sendo este nome fictício para garantir sua identidade preservada, aluna do ensino médio regular e também aluna do AEE, ambas as matrículas na mesma escola pública, relatou em seu atendimento individualizado que estava com muitas dificuldades com um conteúdo que estava sendo trabalhado no ensino regular, na disciplina de Matemática, na parte de Geometria: área de figuras planas.

Embora minha formação inicial seja Licenciatura em Matemática, na época (2019), eu estava com parte da carga horária lotada na Sala de Recursos Multifuncional - SRM (150 h/a) realizando o Atendimento Educacional Especializado - AEE de alunos 
com algum tipo de deficiência, necessidade educacional especial ou altas habilidades da referida escola.

Com base no relato da aluna planejei abordar área com ela partindo do jogo de origem chinesa Tangram. A sala dispunha de um jogo de M.D.F, que lhe foi apresentado e manipulado, mas em seguida foi proposto a confecção do quebra-cabeças para que ao construir as peças, o passo a passo lhe permitisse novas aprendizagens. Para Lorenzato:

\begin{abstract}
A construção de material didático, muitas vezes, é uma oportunidade de aprendizagem. Em sala de aula, é preciso oferecer inúmeras e adequadas oportunidades para que as crianças experimentem, observem, criem, reflitam e verbalizem. As atividades devem ser escolhidas considerando não somente o interesse das crianças, mas também suas necessidades e o estágio de desenvolvimento cognitivo em que se encontram. O professor deve observar atentamente seus alunos, ora como a intenção de verificar se é preciso intervir, no sentido de orientar, ora com a intenção de avaliar seus progressos. As intervenções nunca devem significar uma censura ou críticas às más respostas, mas ser construtivas. (LORENZATO, 2008, p. 20-21)
\end{abstract}

Embora não se tratando de uma criança, essa construção do conhecimento por meio de materiais manipuláveis é muito válida, especialmente por se tratar de uma aluna surda e, para esta, o campo visual ser de muita valia por representar o principal canal de processamento de esquemas de pensamento para a constatação da maioria das informações.

A experiência da construção, com pausas, conversas informais, sem muita rigorosidade, apenas focando no conhecimento que seria adquirido no processo permitiu observações importantes tanto no campo da Matemática quanto da Língua Brasileira de Sinais - Libras.

Para Pimentel, "a utilização de jogos nas aulas de Libras, como em qualquer outro âmbito de ensino, é parte imprescindível no aprendizado dos educandos, pois busca levar a eles uma aprendizagem prazerosa" (PIMENTEL, 2014, p.5).

Diante da dificuldade apresentada pela aluna em compreender para quê e como calcular a área de figuras geométricas planas, optou-se pelo uso do material didático auxiliar (quebra cabeças de origem chinesa chamado Tangram) aliado a uma metodologia lúdica fundamentada em Pimentel (2014, p. 5) e Lorenzato (2008, p. 20-21) como estratégia didática a fim de promover a compreensão e o envolvimento da aluna com o componente curricular. 


\section{Desenvolvimento}

A experiência se deu da seguinte forma: inicialmente com o relato da aluna no seu atendimento individual no AEE e posteriormente com a prática pedagógica a fim de sanar ou pelo menos amenizar as dificuldades relatadas pela discente.

A SRM já tinha em seu material um Tangram de madeira M.D.F, mas a confecção do mesmo fez muito mais sentido para o estudo que estava para acontecer. Incialmente foi apresentado o jogo de madeira, explicado que se tratava de um quebra-cabeças e que com aquelas sete peças era possível formar muitas figuras diferentes. A própria caixa do jogo já trazia algumas figuras como modelo, mas a primeira figura solicitada foi a original: um quadrado com as sete peças.

A aluna apresentou certa dificuldade em montar, pois era seu primeiro contato com o jogo. Embora o quebra-cabeças tenha sido apresentado "montado" em formato de quadrado, posteriormente as peças foram embaralhadas fazendo com que a montagem demandasse um tempo considerável. Apesar do tempo, a atividade proporcionou comparação entre as peças, verificando as que possuíam lados congruentes e testando as possibilidades de encaixe.

Após conseguir montar pela primeira vez, as peças foram novamente embaralhadas e foi solicitado que a aluna realizasse a mesma tarefa. Ainda não foi fácil, mas algumas peças já foram identificadas e agrupadas, como os dois triângulos maiores que imediatamente foram posicionados corretamente. Nesta segunda vez, a aluna sentiuse ainda mais empolgada a montar o quebra-cabeças em formato de quadrado, pois como já conseguira anteriormente, acreditou que realizaria a tarefa em menos tempo, o que de fato aconteceu.

Posterior a essa experiência a educanda foi convidada a construir um Tangram, bem simples, de papel, usando a técnica chamada kirigami, que é a arte de fazer dobras e recortes no papel, com a finalidade de que ela compreendesse/reconhecesse cada figura, suas propriedades, suas características e suas respectivas localizações no quadrado.

Após confeccionado o Tangram, ao ser convidada para unir as sete peças formando um quadrado, a tarefa dessa vez foi realizada sem dificuldades, ou seja, o manuseio, a construção, o tempo que a tarefa demandou fazendo com que a aluna ficasse com o jogo em mãos, pintando e cortando contribuíram para um ganho de habilidade. 
Este é um ponto positivo no viver pedagógico que ao levar a discente a uma compreensão mais clara a estimula a realizar os próximos passos.

$\mathrm{Na}$ confecção do jogo, alguns conceitos da geometria mais elementares que antecedem área, como diagonal, perpendicularismo, paralelismo, adjacência, congruência e ângulo foram abordados em forma de diálogo ao passo que o Tangram ia ganhando forma. Posteriormente aos conceitos e definições conhecidas, "do que é passível de definição", após a aluna realizar sem dificuldades o que lhe foi proposto, lhe foi apresentada a ideia de área do quadrado utilizando régua e dividindo-o em de quadrados de lado um. Após a ideia apresentada, foi solicitado à educanda que a mesma calculasse a área do quadrado formado pelas peças do jogo e do quadrado que integra o conjunto de peças.

Essa foi uma parte divertida que permitiu que comparações fossem feitas como as áreas de quadrados de lados diferentes e trabalhar com números racionais, visto que o lado do quadrado que integrava o conjunto de sete peças do jogo não tinha medida exata.

Partindo da área do quadrado foi possível, sem dificuldades, compreender que a área do triângulo é a metade da área do quadrado, pois a Sandra percebeu que os dois triângulos maiores juntos ocupam a metade da área da figura (que é um quadrado); que cada triângulo menor tem metade da área da peça quadrada; e, por equivalência, ela concluiu que a área da peça paralelogramo e a da peça quadrada são também iguais, pois com os dois triângulos menores foi possível formar o paralelogramo, o quadrado e também o triângulo médio.

Foi impressa uma folha com alguns desenhos possíveis de serem feitos com o Tangram conforme figura 2 (Figura 2). A aluna orgulhosamente montou vários desenhos: figura 2 (Figura 2) e figura 3 (Figura 3).

Figura 2 - Tubarão (primeira montagem após a entrega da folha)

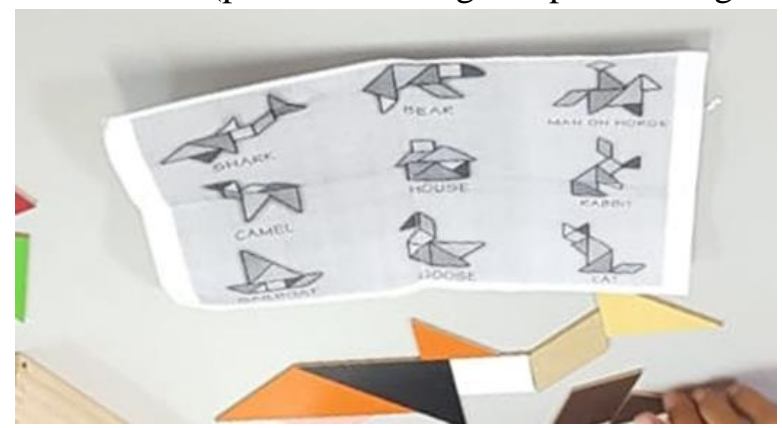

Fonte: Autora (2019) 
Figura 3 - Pato e gato (momento em que concluiu a montagem de todos os desenhos)

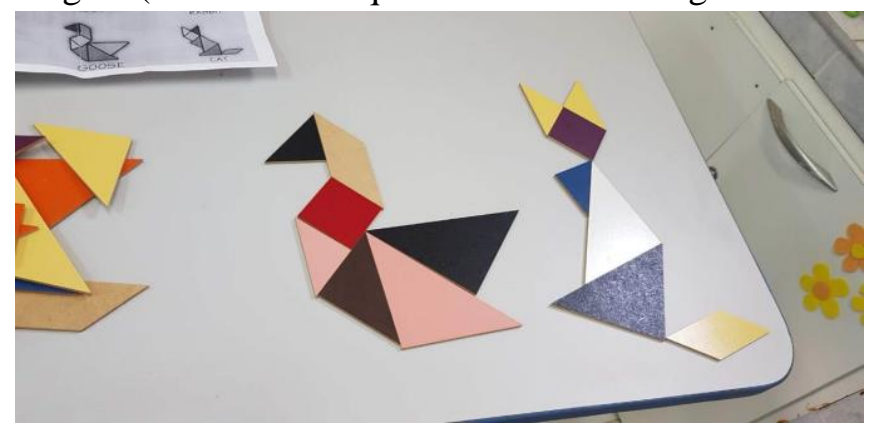

Fonte: Autora (2019)

Após a montagem dos desenhos propostos lhe foi ofertado o último desafio: calcular a área de cada figura formada.

Neste desafio, a aluna deparou-se com a dificuldade de calcular a área das figuras (gato, cisne, barco, ...) por diferirem do quadrado que ela calculara anteriormente. Então, a educanda foi induzida, partindo das comparações que ela já havia feito somando áreas de triângulos para obter as áreas de outras figuras, como o paralelogramo, para que pudesse concluir que a área total de cada figura realizada era a soma das áreas das peças que a compunham.

Em posse da informação que a área total era a soma das áreas das peças, a aluna calculou cuidadosamente a área do cisne, verificando que a mesma coincidira com a área do quadrado e para reforçar seu conhecimento ela ainda calculou a área da casa chegando novamente aos mesmos resultados obtidos anteriormente, e, assim, pôde concluir que a área de qualquer outra figura que ela montasse com aquelas sete peças seria a mesma.

Embora pareça uma apuração simples, visto que os resultados obtidos com o Tangram são conhecidos pela comunidade acadêmica, o uso de um jogo com uma aluna surda vem reafirmar o quão eficaz uma metodologia pautada na ludicidade visual pode ser eficiente, pois compreender área foi um assunto que a discente sempre teve dificuldades, já se encontrava no ensino médio e já havia sido exposta ao assunto por várias vezes durante o Ensino Fundamental estando ainda sem compreender sequer a área do quadrado, o porquê de elevar a medida do lado ao quadrado da fórmula.

A autonomia adquirida, a confiança que a discente demonstrou ao afirmar as últimas conclusões baseada nos últimos resultados que obteve foram importantes não somente para os resultados de área, mas também de percepção de espaço, de outros elementos básicos da Geometria e de sua familiaridade com a Matemática. Segundo ela, 
enquanto aluna surda, nas aulas de Matemática muitas vezes é preciso escolher entre visualizar o que o professor está fazendo na lousa ou prestar atenção à tradução que a intérprete está fazendo do que está sendo falado. Como no atendimento ela contou com as duas situações em um único profissional, Libras e Matemática sendo usadas pela mesma pessoa, sem intérprete, segundo a mesma, isso facilitou.

\section{Resultados e Discussões}

O aprender com presença de elementos físicos, de forma lúdica foi eficaz não somente no ponto isolado área, também abriu cortinas para a aluna, lhe permitindo vislumbrar outros horizontes. Estimulou cognitivamente a discente a querer aprender novas coisas por meio de jogos e/ou materiais manipuláveis.

Vivenciar o exposto foi tão positivo quanto se entende que educação tem que ser: para ambos os lados - discente e docente, até porque docência não é somente entrega, é partilha de saberes com ganhos mútuos. Os horários de atendimento passaram voando pois me permitiram trabalhar com duas paixões pessoais: Matemática e Libras.

Para a aluna, os resultados foram além da mera manipulação de peças e memorização de fórmulas, permitiram a constatação de verdades, a construção das áreas das demais figuras partindo da área do quadrado e consequentemente permitiram atingir melhores resultados.

Foi possível relacionar o conteúdo com o cotidiano saindo das figuras que estavam dispostas na mesa e partindo para outras situações: a área da casa onde a aluna mora, área da capa do caderno, área da sala de atendimento, levando a aluna a não somente entender do que se tratava o conteúdo, mas também reconhecer a importância de dominá-lo.

$\mathrm{O}$ rendimento da aluna, em um bimestre em que a mesma relatava ter dificuldades no assunto, foi positivo fortalecendo que ela, de fato, compreendeu o assunto e adquiriu uma base necessária para solucionar os problemas propostos na avaliação. A sua média bimestral no $3^{\circ}$ período foi 8,5 , contrapondo-se às médias dos dois bimestres anteriores que foram 6,0, reforçando a boa aprendizagem.

Sabe-se que um conjunto de fatores influenciam em uma nota, desde físicos a emocionais e cognitivos, mas considerando que nos bimestres anteriores em que a aluna não relatava dificuldades nos outros saberes do componente curricular ela obteve notas inferiores, pode-se concluir que o Tangram favoreceu para a compreensão do assunto, 
levando-a a novos resultados, mesmo que a estratégia não seja a única responsável, ela tem contribuições positivas. Este relato não pretende atrelar o crescimento de dois pontos e meio na média bimestral da aluna apenas ao jogo, mas certamente a metodologia utilizada no AEE associada ao trabalho e às atividades realizadas no ensino regular favoreceram o crescimento obtido no bimestre. O quadro abaixo apresenta o rendimento por bimestre da aluna na disciplina de Matemática.

Quadro 1 - Médias Bimestrais da aluna de codinome Sandra.

\begin{tabular}{|c|c|c|c|c|}
\hline Bimestre & $\mathbf{1}^{\mathbf{o}}$ & $\mathbf{2}^{\mathbf{o}}$ & $\mathbf{3}^{\mathbf{0}}$ & $\mathbf{4}^{\mathbf{0}}$ \\
\hline Média & 6,0 & 6,0 & 8,5 & 7,0 \\
\hline
\end{tabular}

Fonte: Elaborado pela autora de acordo com cópia do boletim (2019).

Observa-se ainda que a aluna obteve média 7,0 no $4^{\circ}$ bimestre, rendimento positivo, superior ao primeiro semestre, dando indicativo de mais confiança e domínio na área da Matemática.

\section{Considerações Finais}

Relacionar o conteúdo estudado com o cotidiano do aluno é uma maneira prática e tem se mostrado eficaz para o desenvolvimento dos discentes de várias idades/séries, dependendo da forma como a relação é feita e como a aprendizagem é estimulada. No caso da discente surda, relacionar o dia-a-dia com as competências e habilidades que se deseja alcançar, valorizando o visual, foi uma forma de aproximar a aluna do conteúdo fazendo uso de canais que lhe favorecem a compreensão - visão e tato.

O modo como a dificuldade inicial foi encarada foi importante para a obtenção de resultados significativos, promoveram a compreensão e abstração de conteúdos de forma prazerosa sem que houvesse perda da essência do conteúdo.

A utilização do Tangram contribuiu para o desenvolvimento da discente e é um jogo que oferece muita versatilidade, sendo um excelente recurso a ser utilizado em aulas de Matemática seja com o público surdo ou ouvinte. O jogo foi usado de forma individual por se tratar de um caso de AEE, mas por ser um ser um puzzle simples, construí-lo e utilizá-lo em salas de aula numerosas não é desafiador, pelo contrário, pode melhorar a concentração da turma em diversos conteúdos matemáticos abordados. 


\section{Referências}

BRASIL/MEC. Lei no $\mathbf{9} .394$ - Lei de Diretrizes e Bases da Educação Nacional. Brasília, DF: 20 de dezembro de 1996. Disponível em:

<http://www.planalto.gov.br/ccivil_03/leis/19394.htm>. Acesso em: 26 fev. 2021.

MEC/SEESP. Presidência da República. Decreto no 7.611 , de 17 de novembro de 2011. Disponível em: <http://www.planalto.gov.br/ccivil_03/_ato20112014/2011/decreto/d7611.htm>. Acesso em: 26 fev. 2021.

MEC/SEESP. Manual de Orientação: Programa de Implantação de Sala de Recursos Multifuncionais. 2010. Disponível em $<$ http://portal.mec.gov.br/index.php?option=com_docman\&view=download\&alias=993 6-manual-orientacao-programa-implantacao-salas-recursosmultifuncionais\&Itemid=30192 >. Acesso em: $10 \mathrm{fev} .2021$.

. Secretaria de Educação Fundamental. Parâmetros curriculares nacionais: matemática /Secretaria de Educação Fundamental. - Brasília: MEC/SEF, 1997

D’AMBROSIO, B. S. Como ensinar matemática hoje? Temas e Debates. SBEM. Ano II. N2. Brasilia. 1989. P. 15-19.

DIZEU, L. C. T. B; CAPORALI, S. A. A língua de sinais construindo o surdo como sujeito. Revista Educação \& Sociedade. Campinas - SP, v.26, n.91, 2005.

KALEFF, A. M. M. R. Vendo e entendendo poliedros: do desenho ao cálculo do volume através de quebra-cabeças e outros materiais concretos. Niterói: EdUFF, 2003.

LORENZATO, S. Educação Infantil e Percepção Matemática. Coleção Formação de Professores. 2 ed. Campinas-SP: Autores Associados, 2008.

MOURA, Manoel O. de. A serie busca no jogo: do lúdico na matemática. A educação matemática em revista. Blumenau: SBEM, v.2, n. 3, 1994.

PIMENTEL, I. F; Sabino, E. B. Jogos adaptados utilizados como recurso pedagógico facilitador para o ensino de Libras em Castanhal-PA. Campina Grande: Realize Eventos e Editora. Campina Grande, 2014.

SILVA, M. T. Tangram e Geoplano: Uma abordagem didática. TCC (Monografia) Licenciatura em Matemática - Universidade Federal de Santa Catarina. FlorianópolisSC, 2007.

VYGOTSKY, L. S. e LEONTIEV. ALEXIS. Linguagem, desenvolvimento e aprendizagem. São Paulo: Edusp, 1998. 